\title{
Jackfruit seed flour: Processing technologies and applications
}

\section{Prajakta Mandave, Hanuman Bobade and Sachin Patil}

Received : 10.04.2018; Accepted : 13.04.2018

See end of the Paper for authors' affiliation

Correspondence to :

Prajakta Mandave Department of Agricultural Engineering, Maharashtra Institute of Technology, Aurangabad (M.S.) India
- Abstract : Jackfruit (Artocarpus heterophyllus Lam) is the largest produced fruit in the world. It is originated from India. Climate required for growing jackfruit is tropical and subtropical. It is indigenous food crop. Humid and hot region suitable for growth of this tree. It is not tolerate cold and higher altitude also frost and drought. Jackfruit contains some vitamins like vitamin A, vitamin C, thiamine and riboûavin also some minerals like calcium, potassium, iron, sodium, zinc, niacin and many other nutrient. Jackfruit contain antioxidant which help in prevention from free radicals. It contain potassium and calcium so it regulate the blood pressure and beneficial to bones growth. It also helpful as anti-inûammatory, antibacterial, anticariogenic, antifungal and in inhibition of melanin biosynthesis, wound healing effects. The jackfruit peels utilization only $10 \%$ for food applications that is pectin extraction. While $90 \%$ is for non-edible applications of bioûlm, biosorbent, biohydrogen, and activated carbon. It contains phytonutrients like lignans, isoûavones and saponins, their health beneûts are wide-ranging from anticancer to antihypertensive, antiaging, antioxidant and antiulcer. Protein, dietary fibre and carbohydrate contents of jackfruit seeds is $13.50 \%, 3.19 \%$ and $79.34 \%$, respectively. The jackfruit seed has been utilized for processing like flour for bakery, extruded products, chapaties, starch extraction and confectionary. Application of jackfruit seeds in medicines, seeds are believed to be helpful in digestion.

- Key words : Health benefits, Indigenous, Jackfruit, Phytonutrients, Seed flour

- How to cite this paper : Mandave, Prajakta, Bobade, Hanuman and Patil, Sachin (2018). Jackfruit seed flour: Processing technologies and applications. Internat. J. Agric. Engg., 11(Sp. Issue) : 149-154, DOI: 10.15740/HAS/IJAE/11.Sp. Issue/149-154. 